\title{
TEKNIK SABLON SEBAGAI MEDIA APRESIASI KARYA DESAIN PADA TSHIRT
}

\author{
Muhammad Imam Tobroni \\ Jurusan Desain Komunikasi Visual, Fakultas Komunikasi dan Multimedia, Bina Nusantara University \\ Jln. K.H. Syahdan No. 9, Palmerah, Jakarta Barat 11480
}

\begin{abstract}
Screen printing is one of printing techniques. It has its own characteristic and uniqueness in the printing process, so it has customer likeability. Besides as printing media, screen printing is a media to promote and to gather creative ideas in reproduction printing technique. Communication could be understood as message, idea or information delivery process to other people that using specific facilities or equipment to influence or change the receiver's behavior. T-Shirt as one message delivery media has important part in creative industry. Screen printing technique has different characteristic. T-Shirt as screen printing media is highly effective in supporting promotion and design work appreciation media.
\end{abstract}

Keywords: screen printing, media, communication, t-shirt, design

\begin{abstract}
ABSTRAK
Screen printing atau yang secara umum lebih dikenal sablon adalah sebuah teknik cetak. Sablon mempunyai karakteristik dan mempunyai keunikan sendiri dalam proses cetaknya, sehingga media ini sangat disukai konsumen. Selain sebagai media cetak, sablon juga sebagai media untuk promosi dan media untuk menuangkan ide-ide kreatif dalam teknik cetak reproduksi. Komunikasi dapat dipahami sebagai proses penyampaian pesan, ide, atau informasi kepada orang lain dengan menggunakan sarana atau alat tertentu guna mempengaruhi atau mengubah perilaku penerima pesan. T-shirt sebagai salah satu media penyampai pesan mempunyai peranan yang penting dalam industri kreatif. Teknik cetak sablon mempunyai karakteristik yang berbeda. T-shirt sebagai media cetak sablon sangat efektif dalam mendukung promosi dan media apresiasi karya desain.
\end{abstract}

Kata kunci: sablon, media, komunikasi, t-shirt, desain 


\section{PENDAHULUAN}

Sektor industri diharapkan akan dapat menjadi tumpuan dalam pertumbuhan perekonomian. Perkembangan sektor industri juga disumbang karena adanya pertumbuhan kewirausahaan dalam masyarakat, perdagangan barang dan jasa dengan merek terdaftar yang dikenal luas oleh masyarakat, penemuan dan penerapan teknologi dalam proses produksi yang terbukti bermanfaat bagi masyarakat, penerapan perdagangan modern dengan sistim manajemen yang lebih baik. Agar lebih mendorong tumbuhnya aktivitas di dalam masyarakat untuk selalu menciptakan kreasi-kreasi desain baru di bidang industri. Industri cetak kemajunnya sangat cepat, seiring dengan cepatnya teknologi dan pertumbuhan ekonomi. Diperlukan sebuah media yang efektif untuk menyampaikan pesan kreatif untuk menunjang berhasilnya promosi.

\section{Komunikasi}

Komunikasi massa merupakan salah satu Jenis komunikasi, selain komunikasi intrapersonal, Komunikasi intrapersonal, komunikasi kelompok dan komunikasi organisasi. Perkembangan komunikasi sangat pesat saat ditemukan alat mesin cetak oleh John Guttenberg tahun 1445 yang dianngap awal dari lahirnya komunikasi massa. Komunikasi massa merupakan proses komunikasi melalui media massa atau komunikasi terhadap orang banyak (massa) dengan menggunakan media tertentu.

Rivers, Jensen, \& Peterson (2003) membedakan antara communication dan communications. Arti dari communication adalah proses komunikasi. Communications adalah perangkat teknis yang digunakan dalam proses komunikasi, seperti gendering, asap, butir batu, telegram, telephon, materi cetak, siaran dan film. Selanjutnya, menurut Rivers, Jensen, \& Peterson (2003), komunikasi massa dapat diartikan dalam dua cara, yaitu komunikasi oleh media dan komunikasi oleh massa. Namun, komunikasi massa tidak berarti komunikasi untuk setiap orang. Pasalnya, media cenderung memilih khalayak; demikian pula, khalayak pun memilih-milih media. Karakeristik komunikasi massa secara umum adalah: (1) pesan bersifat universal, umum dan ditujukan kepada khalayak (orang banyak); (2) menimbulkan keserampakan dan keserentakan penerimaan oleh massa; (3) komunikan bersifat anonim dan heterogen; (4) berlangsungnya satu arah; (5) respon komunikan atau audience tidak langsung diketahui.

Komunikasi dapat dipahami sebagai proses penyampaian pesan, ide, atau informasi kepada orang lain dengan menggunakan sarana atau alat tertentu guna mempengaruhi atau mengubah perilaku penerima pesan. T-shirt sebagai salah satu media penyampai pesan mempunyai peranan yang penting dalam industri kreatif. Pesan-pesan yang komunikatif menjadi tolak ukur akan berhasilnya sebuah proses komunikasi yang efektif. T-shirt adalah sebuah media yang tepat digunakan sebagai sarana promosi. Sebagai salah satu jenis pakaian yang modelnya paling lama bertahan. Produk ini sangat familiar di semua kalangan, tidak peduli dari mana asalnya, apapun sukunya, pokoknya melewati semua batas itu.

\section{Sejarah Cetak Saring}

Menengok sejarah cetak saring atau cetak sablon telah lama dikenal dan digunakan oleh bangsa Jepang sejak tahun 1664, abad ke-17. Ketika itu, Yuzensai Miyasaki dan Zisukeo Mirose mengembangkannya dengan menyablon kain kimono beraneka motif yang sebelumnya dibuat motif kimono dengan tulis tangan. Ternyata lebih menekan biaya sehingga kimono motif sablon mulai banyak digunakan oleh masyarakat Jepang. 


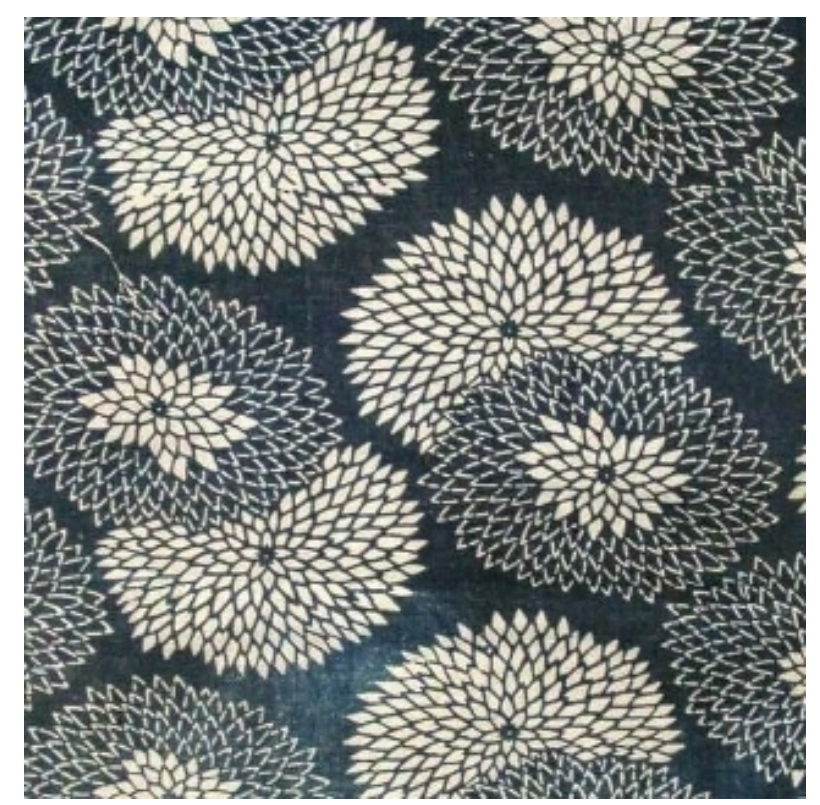

Gambar 1 Katazome Menggunakan Cetak Stensil Katagami

Sejak itu, teknik cetak saring terus berkembang dan merambah ke berbagai negara. Pada tahun 1907, pria berkebangsaan Inggris, Samuel Simon, mengembangkan teknik sablon menggunakan chiffon sebagai pola untuk mencetak. Chiffon merupakan bahan rajut yang terbuat dari benang sutera halus. Bahan rajut inilah yang merupakan cikal bakal kain gasa untuk menyablon. Menyablon dengan chiffon caranya tinta yang akan dicetak dialirkan melalui kain gasa atau kain saring, sehingga teknik ini juga disebut silk screen printing yang berarti mencetak dengan menggunakan kain saring sutera. Setelah Perang Dunia II, teknik cetak saring terus berkembang pesat, inovasi-inovasi terus dilakukan sehingga munculah teknik-teknik baru, yang semula membuat motif secara sederhana kemudian berkembang dengan digunakannya komputer untuk membuat motif yang lebih bervariasi.

Teknologi screenprint di atas kaos katun baru dimulai awal "60-an dan setelah itu barulah bermunculan berbagai bentuk kaos baru, seperti tank top, muscle shirt, scoop neck, v-neck dsb. Berbagai bentuk, gambar, atau kata-kata dalam kaos merupakan pesan akan pengalaman, perilaku dan status sosial. Kaos oblong mengkomunikasikan berbagai lokasi atau identitas sosial: tempat (HRC, Borobudur, Bali, Yogyakarta), bisnis (Coca Cola, Yamaha, Suzuki), tim (MU, Inter Milan), konser atau acara kesenian (Jakjazz), komoditas yang dianggap bernilai (VW, Harley Davidson), sementara banyak juga yang mengkomunikasikan slogan (kaos-kaos Dagadu, Joger).

\section{Sejarah T-Shirt}

T-shirt atau yang lebih sering dikenal dengan kaos,diperkirakan muncul antara akhir abad ke19 hingga awal abad ke-20. Kaos berbahan katun biasanya dipakai oleh tentara Eropa sebagai pakaian dalam (di balik seragam), dan biasanya dipakai sebagai pakaian luar jika mereka beristirahat di udara siang yang panas. Pada perang Dunia II tshirt menjadi perlengkapan standar dalam pakaian militer di Eropa dan Amerika Serikat (T-Shirt King).

Pada tahun 1947 kaos mulai dikenal di seluruh dunia lewat John Wayne, Marlon Brando dalam filmnya A Streetcar Named Desire tahun1951 dan James Dean yang memakai pakaian dalam tersebut untuk pakaian luar dalam film-film mereka. Dan puncaknya adalah ketika James Dean mengenakan kaos sebagai symbol pemberontakan kaum muda dalam Rebel Without A Cause (1955). 


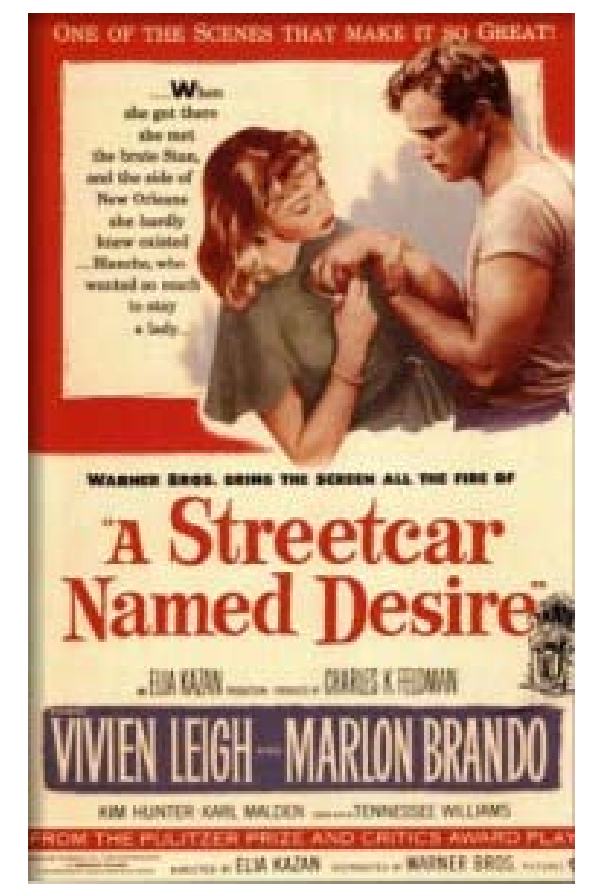

Gambar 2 A Streetcar Named Desire (1951)

Semenjak saat itulah revolusi T-shirt terjadi secara total. Para penggiat bisnis menyadari bahwa T-shirt dapat menjadi medium promosi yang amat efektif serta efesien. Segala persyaratan sebagai medium promosi yang baik ada di T-shirt. Murah, mobile, fungsional, dapat dijadikan suvenir, dan seterusnya.

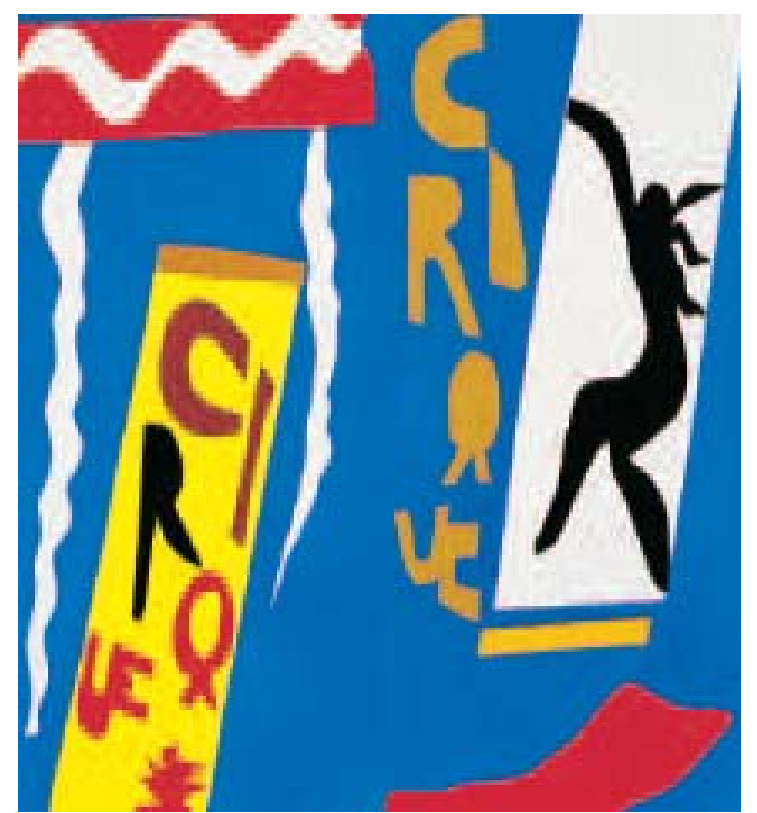

Gambar 3 Henri Matisse. Jazz (Cirque). 1947. 

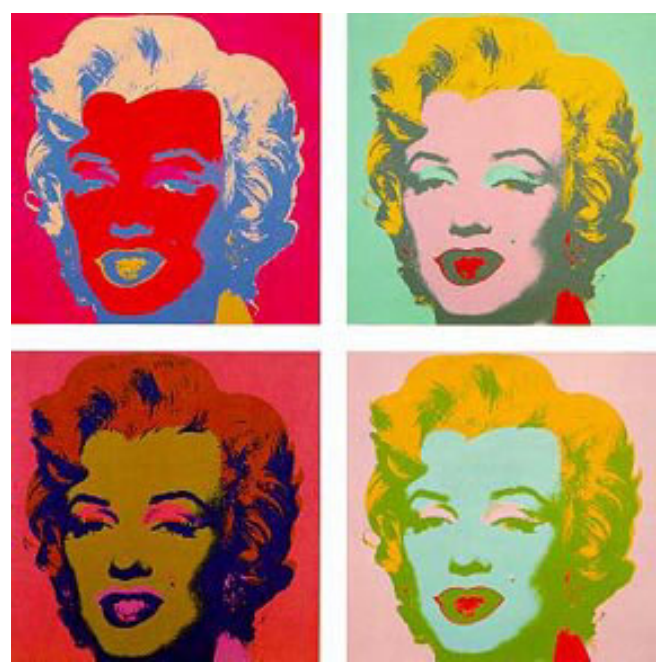

Gambar 4 Andy Warhol, Marilyn 1967

Di Indonesia, konon, masuknya benda ini karena dibawa oleh orang-orang Belanda. Namun ketika itu perkembangannya tidak pesat, sebab benda ini mempunyai nilai gengsi tingkat tinggi, dan di Indonesia teknologi pemintalannya belum maju, Akibatnya benda ini termasuk barang mahal. Namun demikian, kaos baru menampakkan perkembangan yang signifikan hingga merambah ke segenap pelosok pedesaan sekitar awal tahun 1970. Ketika itu wujudnya masih konvensional. Berwarna putih, bahan katun-halus-tipis, melekat ketat di badan dan hanya untuk kaum pria. Beberapa merek yang terkenal waktu itu adalah Swan dan 77. Ada juga merek Cabe Rawit, Kembang Manggis, dan lainlain.

Tidak hanya di Amerika dan Eropa, di Indonesia pun kaos sudah menjadi media berekspresi. Kaos yang berwarna putih itu diberi gambar vinyet, dan waktu itu sempat menjadi tren/mode di kalangan anak muda Indonesia. Tapi tidak lama. Berikutnya vinyet digeser oleh tulisan-tulisan yang berwarna-warni. Tekniknya sepeprti sablon. Selain itu, ada juga gambar-gambar koboi, orang-orang berambut gondrong, dan lain-lain. Warna bahan kaos pun sudah semarak, yaitu merah, hitam, biru kuning. Dan, tren kaos rupa-rupanya direkam pula oleh Kartunis GM Sudarta melalui tokoh Om Pasikom dan kemenakannya dengan tajuk Generasi Kaos Oblong.

\section{Fungsi T-shirt}

Semenjak revolusi T-shirt, saat itu diproduksi secara masal oleh industri. Para penggiat bisnis menyadari bahwa T-shirt dapat menjadi medium promosi yang amat efektif serta efesien. Segala persyaratan sebagai medium promosi yang baik ada di T-shirt. Murah, mobile, fungsional, dapat dijadikan suvenir, dan seterusnya. sekarang ini kaos juga dipakai untuk mengkomunikasikan apa yang bukan bagian dari identitas seseorang. Di saat yang bersamaan, kelompok-kelompok tertentu, misalnya komunitas punk, atau organisasi politik, juga menyadari bahwa T-shirt dapat menjadi medium propaganda yang sempurna selain medium yang telah ada. Statement apapun dapat tercetak diatasnya, tahan lama, dan penyebarannya mampu melewati batas-batas yang tidak dapat dicapai oleh medium lain, seperti misalnya poster.

Dengan semakin tumbuhnya industri periklanan, kaos merupakan bilboards mini yang cukup efektif untuk mengkomunikasikan sebuah produk, sebagaimana mengkomunikasikan diri atau identitas. Seringkali kaos dijadikan iklan berjalan yang oleh pengiklan kadang-kadang dibagikan secara gratis. Di Indonesia, adalah hal yang biasa banyak orang berebut mendapatkan pembagian kaos 
dari OPP pada saat Pemilu. Perusahaan-perusahaan sekarang ini juga membuat kaos dengan nama atau logo perusahaan yang tertera di atasnya (Coca Cola, Reebok, Nike, Wilson), dan menjualnya di tokotoko sebagai pakaian produksi massal yang siap pakai. Bagi sejumlah besar pemakainya, tentu memakai kaos oblong tidak dimaksudkan sebagai iklan, melainkan sebagai indikasi status dan pendapatan pemakainya, loyalitas atau kepercayaan pada satu produk.

Kaos-kaos buatan perusahaan tertentu dianggap mewakili gaya hidup atau selera yang khas, selain sekaligus si pemakai mengiklankan perusahaan pembuatnya. Misalnya kaos bermerek Benetton, Ralph Lauren atau Calvin Klein. Simbol-simbol tertentu pada kaos, seperti buaya kecil atau kuda poni dan pemain polo kecil (dan berbagai variannya), juga sangat penting. Simbol-simbol ini bukan hanya menunjukkan status pemakainya yang mampu mengkonsumsi pakaian buatan desainer mahal, tetapi juga status dalam sistem fashion itu sendiri.

Dalam kaitannya dengan pola penempatan ruang, sebagai pakaian dalam kaos adalah pakaian privat . Tetapi kemudian dengan negosiasi lewat media massa dan penemuan bahan serta model-model baru, kaos perlahan mulai tampil sebagai pakaian publik. Karena itu, sejalan dengan kecenderungan kehidupan modern, perjalanan kaos dari ruang privat ke ruang publik ini merupakan ekspansi ruang privat atas ruang publik (privatisasi ruang publik). Sementara dalam kaitannya dengan pola pemanfaatan waktu, kaos menunjukkan bagaimana waktu senggang semakin berhasil mengekspansi waktu yang lain dalam kehidupan sehari-hari.

\section{Cetak Saring}

Istilah cetak saring di Indonesia lebih populer dengan sebutan cetak sablon. Kata sablon berasal dari bahasa Belanda, yaitu Schablon, sehingga dalam bahasa serapan menjadi sablon (Nusantara, 2007). Sablon dapat didefinisikan sebagai pola berdesain yang dapat dilukis berdasarkan contoh. Cetak sablon adalah mencetak dengan menggunakan model cetakan atau mal. Cetak saring adalah mencetak dengan menggunakan kain gasa yang dibingkai disebut screen. Proses Pembuatan Cetak saring bisa dilakukan dengan mesin seperti yang dilakukan pada pabrik printing dan bisa dilakukan secara manual seperti yang dilakukan oleh home Industri menengah dan kecil. Teknik pembuatan desain motif dengan cara: tanpa kodatrace atau menggunakan kertas warna gelap yang diafdruk, dengan kodatrace dan komputer atau teknik sparasi warna (CMYK). Zat warna yang digunakan antara lain zat warna pigmen dan zat warna reaktif, walaupun hamper semua jenis zat warna untuk tekstil bisa digunakan. Kain tekstil yang digunakan hampir semua jenis kain tekstil, dari serat sintetis atau serat alam yang mempunyai permukaan datar bisa disablon dengan menggunakan screen.

Cetak saring atau sablon atau screen printing merupakan bagian dari ilmu grafika terapan yang bersifat praktis. Cetak saring dapat diartikan kegiatan cetak mencetak dengan menggunakan kain gasa/kasa yang biasa disebut screen (Nusantara, 2007). Pada umumnya cetak mencetak dilakukan pada setiap benda padat yang datar tetapi dapat juga dilakukan di atas bentuk yang melingkar. Pada prinsipnya cetak mencetak pada berbagai macam benda padat adalah sama. Perbedaannya terletak pada jenis cat / tinta yang digunakan dan jenis produk yang akan dicetak.

\section{Persiapan Material}

\section{Material Pra Cetak}

Tahap awal yang harus dikerjakan dalam proses sablon adalah pembuatan desain, di mana desain tersebut yang akan dipindahkan ke screen dengan teknik afdruk. Desain ini biasa disebut sebagai klise, film master atau gambar acuan. Teknik menggambar ada dua jenis pertama, dengan cara manual atau menggambar langsung. Kedua, dengan menggunakan aplikasi komputer (CorelDRAW, Adobe Illustrator, Adobe Photoshop, dan lain-lain). Pada dasarnya kedua cara ini 
sama yakni menghasilkan gambar yang untuk di afdrukan ke screen. Persyaratan utama gambar tersebut adalah tidak tembus cahaya. Bagian ini akan menghalangi cahaya masuk dan menghasilkan bagian yang berlobang (tembus cat) atau bagian gambar.

\section{Design}

Mempunyai tingkat kekontrasan yang tinggi, film hanya membaca positif dan negatif, apabila ada desain menggunakan warna abu-abu, digunakan titik yang solid. Pergunakan garis yang cukup besar untuk menghindari desain tidak bisa terekam saat proses afdruk. Untuk pengisian warna, digunakan warna yang solid.

\section{Meja Gambar}

Meja gambar digunakan untuk membuat desain motif untuk cetak saring dan untuk memindah gambar ke film atau gambar acuan.

\section{Film}

\section{Kodaktrace}

Kodaktrace digunakan sebagai film diapositif yang mempunyai karakteristik dari bahan plastik dengan mempunyai 2 permukaan. Permukaan yang kasar dipergunkan untuk membuat gambar. Cetakan dengan menggunakan printer laser dan mencetak di atas kalkir 70 gram atau 80 gram.

\section{Opaque Ink dan Tinta Cina}

Tinta Cina digunakan untuk menggambar memisahkan motif tiap warna pada kertas HVS /kalkir atau kodaktrace dengan menggunakan kuas. Opaque Ink untuk menggambar memisahkan motif tiap warna pada kodaktrace.

\section{Material Afdruk}

\section{Meja Afdruk}

Meja yang dilengkapi dengan lampu neon atau TL 6 × 20 watt untuk hemat energi (terutama digunakan apabila cuaca mendung atau hujan). Menggunakan alas kaca bening bagian atas 0,5 sampai $1 \mathrm{~cm}$.

\section{Perekam Film}

Obat peka cahaya merupakan larutan pokok dalam proses afdruk screen, merupakan campuran antara emulsi dan sensitizer (cairan peka cahaya). Di pasaran bahan ini terdapat dalam satu kemasan dus kecil yang berisi dua buah botol. Botol besar berisi cairan emulsi, botol kecil berisi cairan sensitizer (larutan Kromatin). Digunakan untuk melapisi screen pada proses afdruk, pelapisan dilakukan pada ruang gelap atau ada cahaya lampu merah.

\section{Penghapus Screen}

Ulano 5 atau kaporit digunakan untuk menghapus obat peka cahaya pada screen apabila sudah tidak digunakan. Ulano 8 untuk menghapus bayangan pada screen.

\section{Hairdryer}

Untuk mengeringkan screen setelah diolesi obat peka cahaya dan mengeringkan hasil cetakan pada kain.

\section{Hand Sprayer}

Alat penyemprot untuk membuat lubang screen setelah proses penyinaran dan untuk membersihkan screen setelah penyablonan. Hand sprayer dilengkapi dengan selang plastik yang dihubungkan pada kran air. 


\section{Karet Busa 5 cm}

Untuk menyangga bagian dalam screen pada waktu afdruk supaya permukaan screen datar.

\section{Pemberat}

Sebagai pemberat agar posisi film tidak bergeser dan stabil posisinya.

\section{Alat-Alat Bantu}

Pengaduk, mangkok tempat pencampur obat, cutter, lakban, gunting

\section{Material Cetak}

\section{Screen}

Screen terdiri dari kerangka kayu dan monyl atau kain sutera yang digunakan untuk mencetak gambar pada benda yang akan disablon. Kain ini berpori-pori dan bertekstur sangat halus menyerupai kain sutera. Lubang pori-pori pada screen ini berfungsi menyaring dan menentukan jumlah zat warna yang keluar. Ada bermacam-macam jenis kain screen, jenis kain screen terbagi atas kualitas, bahan dasar serat, warna dan besar kecilnya lubang.

\section{Rakel}

Rakel merupakan alat yang digunakan untuk menyaput zat warna ke atas permukaan kain atau media cetak. Terbuat dari karet yang dijepit pada kayu atau aluminium. Ada 5 jenis rakel, yaitu: rakel tumpul, bulat, lancip, miring dan persegi.

\section{Bahan Cat}

Tinta bahan kaos terdiri dari 2 jenis tinta, yaitu tinta yang berbasis air atau waterbase inks dan tinta yang berbasis minyak atau solvenbase. Tinta solvenbase sering disebut dengan istilah plastisol.

\section{Jenis Cat Waterbase}

\section{Cat Rubber}

Tinta ini digunakan khusus untuk sablon diatas kain gelap. Sebab tinta ini bersifat pekat, dapat menutup permukaan warna kain dengan baik. Tinta rubber umumnya digunakan untuk underbase, underbase sendiri difungsingkan sebagai penutup warna kain sebelum penyablonan warna-warna di atasnya. Tinta rubber sendiri dibagi menjadi dua jenis untuk dua fungsi kegunaan. Jenis pertama adalah tinta rubber white yang digunakan untuk underbase/dasar, bisa juga digunakan untuk mendapatkan warna-warna pastel/muda. Jenis kedua adalah rubber color yang digunakan untuk pencampuran warna-warna tua. Untuk mendapatkan warna putih yang bersih dan cemerlang, campurkan tinta rubber white dengan sedikit pigmen/pewarna berwarna nila atau ungu.

\section{Cat Transparan}

Umumnya disebut dengan coating, karena dapat difungsikan sebagai pelapisan hasil sablon, sehingga hasil sablon lebih cemerlang atau mengkilap. Tinta ini memiliki bentuk seperti tinta extender yang transparan, tetapi memiliki kandungan yang lebih kuat atau lebih keras. Tinta ini baik sekali untuk teknik penyablonan separasi empat warna dengan terlebih dahulu memberikan rubber white pada permukaan bahannya.

\section{Cat Extender}

Tinta in bersifat transparan, hanya cocok untuk penggunaan diatas bahan putih atau bahan-bahan berwarna terang. Sifat dari cat ini adalah menyatu atau menyerap pada bahan. 


\section{Cat Super White}

Tinta ini hampir sama jenisnya dengan tinta rubber, terdiri dari dua jenis yaitu white dan color. Tinta ini sifatnya lebih mendekati tinta extender yaitu menyatu dengan bahan dan transparan, serta dapat disablon diatas dasar bahan berwarna gelap.

\section{Cat Puff/Timbul}

Tinta ini terdapat pada kedua jenis tinta baik underbase maupun plastisol. Tinta ini memerlukan pemanasan yang akan mengakibatkan tinta ini mengembang dengan efek timbul.

\section{Cat Solvenbase/Plastisol}

Tinta ini berbahan dasar PVC dan harganya cukup mahal serta membutuhkan peralatan khusus untuk pengeringannya. Sebab tinta ini tidak dapat kering dengan sendirinya seperti tinta waterbase pada umumnya. Untuk dapat kering dengan baik, tinta ini memerlukan suhu mencapai 160 derajat celcius serta membutuhkan beberapa peralatan seperti conveyor curing dan flash curing. Setelah pengeringan dengan benar, tinta plastisol ini memiliki daya rekat yang sangat baik. Tinta ini sering digunakan untuk menciptakan efek-efek yang menakjubkan seperti high density. Dan t-shirt yang menggunakan tinta plastisol selalu diberi peringatan do not iron on design, sebab tinta ini akan meleleh jika terkena panas secara langsung dari setrika.

\section{Jenis Cat Plastisol}

\section{Cat All Purpose}

Tinta ini berbentuk transparan, bersifat seperti extender pada tinta waterbase. Sebab tinta ini hanya baik digunakan pada kain berwarna putih atau terang.

\section{Cat High Opacity}

Tinta ini mempunyai sifat seperti rubber dalam waterbase, hanya saja tinta ini mempunyai daya tutup yang lebih baik pada permukaan bahan jika dibandingkan dengan tinta rubber. Tinta ini dapat digunakan untuk teknik high density.

\section{Cat Athletic Plastisol}

Tinta ini bersifat lentur atau elastis sehingga sangat cocok untuk penyablonan diatas kain polymesh,spandex atau kain dengan motif berlubang-lubang.

\section{Cork Base}

Berjenis plastisol, tinta ini dapat digunakan untuk teknik high density yang akan menghasilkan efek seperti busa atau gabus. Tinta ini memiliki kelenturan dan fleksibelitas yang tinggi sehingga cukup baik untuk penyablonan diatas bahan yang memiliki kelenturan tinggi seperti bahan spandek dan rib. Tinta ini juga tidak diperbolehkan untuk di dry clean, bleach atau disetrika.

\section{Shimmer Gold \& Base}

Tinta dari jenis plastisol ini diformulasikan untuk menghasilkan warna seperti metalik. Tinta ini berbentuk pasta dan siap pakai. Tinta ini sangat baik digunakan untuk heat transfer, baik itu cold peel maupun hot peel. Sangat baik digunakan pada kain knitting, cotton, polyster dan rayon. Tidak disarankan untuk pemakaian pada kain jenis nylon atau lycra.

\section{High Density Clear}

Tinta yang bersifat transparan, tinta ini menghasilkan efek sablon yang mengkilap dan terkesan basah.

\section{Wilflex Luna Clear}

Tinta plastisol transparan yang tidak terlihat dengan sinar lampu biasa, akan muncul jika terkena sinar ultraviolet. 


\section{Natural Suede}

Tinta plastisol yang menghasilkan efek kulit yang sangat lembut.

\section{Jenis Cat dan Teknik Lainnya}

\section{Yellow Sparkle}

Bubuk yang diformulasikan untuk menimbulkan kesan berkelip-kelip, serta memiliki tampilan yang glosy. Untuk mencetak bubuk ini, sebelumnya harus mencetakkan tinta plastisol sebagai dasar sekaligus sebagai perekat bubuk ini.

\section{Foil Transfer}

Aluminium foil dalam bentuk lembaran seperti kertas. Selain warna silver dan gold, foil juga tersedia dalam macam warna dan motif. Untuk media tempelnya foil ini membutuhkan lem khusus.

\section{Flock}

Teknik sablon yang menghasilkan efek cetakan seperti beludru. Terdapat dua jenis flock, bubuk dan lembaran. Untuk lembaran membutuhkan lem khusus sebagai media perekatnya.

\section{Sugar Printing}

Aplikasi sablon yang berbentuk bubuk transparan mirip gula pasir.

\section{Glow in the Dark}

Berbentuk serbuk yang menyerap dan memantulkan sinarnya kembali didalam ruangan gelap.

\section{Reflective Powder}

Serbuk yang dapat memantulkan sinar jika terkena cahaya lampu atau sinar matahari.

\section{Discharge Agent}

Adalah bahan kimia yang digunakan untuk mencabut warna dasar kain, sehingga warna bahan menjadi putih atau grey. Dan untuk mendapatkan hasil yang maksimal, bahan pewarna kainnya harus dipilih dengan yang dischargeable.

\section{Distressed atau Vintage}

Teknik inovasi grafik dengan membuat tekstur sehingga gambar terlihat pecah-pecah dan terlihat using atau kuno.

\section{Shatter Base}

Jenis tinta untuk menciptakan kesan pecah (crack). Tinta ini diciptakan agar mudah pecah saat mongering dan untuk pengeringan membutuhkan flash curing.

\section{Rock Base}

Teknik high density menggunakan tinta rock base untuk menghasilkan cetakan dengan permukaan kasar seperti batu.

\section{Sublimation Transfer}

Gambar yang dicetak diatas kertas transfer, yang kemudian ditransfer ke kaos menggunakan hotpress. Sublimation transfer umumnya terbagi dalam menjadi dua jenis, hot peel dan cold peel.

\section{Hot Peel}

Gambar yang di print di atas kertas transfer. 


\section{Cold Peel}

Kertas transfer yang berisi gambar jadi dengan berbagai jenis pilihan. Jenis cold peel ini jika diaplikasikan diatas kain kaos akan menghasilkan tekstur seperti tinta rubber, dan dapat diaplikasikan diatas dasar bahan terang maupun gelap. Sebab dalam pembuatannya cold peel menggunakan tinta plastisol.

\section{Rhinestones Heat Press}

Aplikasi yang digunakan untuk dekorasi dalam garmen, mempunyai beragam nama sesuai dengan bahan yang digunakan, anatara lain nailheats, rhinestones dan swarovski crystals. Cara pengaplikasiaannya hanya dengan memanaskannya dengan mesin hot press pada suhu 160 derajat celcius selama 10 detik.

\section{High Frequency Welding}

Proses aplikasi menggunakan mesin high frequency, seperti aplikasi plastik PVC di atas kain.

\section{Emboss Print}

Aplikasi yang menggunakan mesin press tekanan tinggi untuk menciptakan hasil emboss diatas bahan.

\section{Pewarna}

Zat warna untuk sablon hampir semua jenis zat warna dalam tekstil bisa digunakan dalam penyablonan. Tetapi zat warna pigmen paling bayak digunakan contohnya, sandy colour walaupun sifatnya hanya menempel pada permukaan serat tekstil atau kain, tetapi penggunaannya sangat mudah, seperti untuk warna pokok Merah, Biru, Kuning dan Hitam atau CMYK (Cian, Magenta, Yellow dan Hitam). Selain itu dalam Industri besar dan kecil banyak menggunakan zat warna Reaktif (Remazol, Procion dan Cibacron) dan Zat warna Dispersi untuk kain sintetis.

\section{Pengencer}

Binder maupun air, sebagai pengencer bahan cat apabila cat sudah mengental. Tingkat keenceran bahan cat terbantung dengan kebutuhan.

\section{Catok}

Alat penjepit screen yang posisinya pada meja sablon, fungsinya adalah supaya posisi screen tidak berubah dan tetap stabil seperit pada posisinya.

\section{Meja Sablon}

Meja untuk menyablon kaos atau lembaran yang ukurannya kecil, dilengkapi dengan klem penjepit dan dapat diputar, cukup untuk empat screen.

\section{Papan Landasan}

Hidronal G merupakan lem kain, sebagai pelapis pada papan landasan untuk menempelkan kain atau kaos yang akan disablon supaya permukaan rata dan tidak lepas pada penyablonan warna berikutnya.

\section{T-shirt (Media Sablon)}

Kaos untuk disablon bisa dalam bentuk lembaran tetapi sudah dipotong, biasanya bagian depan saja yang disablon sehingga apabila terjadi kesalahan bisa lebih hemat. Selain selendang untuk disablon, kain ukuran taplak meja atau kain lembaran untuk membuat tas, perlu diperhatikan bahan yang bisa disablon yaitu bahan yang permukaan datar atau halus. 


\section{Proses Afdruk}

\section{Pencampuran Obat}

Pelapisan (coating) screen dimulai dengan membuat larutan afdruk atau obat peka cahaya yaitu campuran emulsi dan sensitizer. Aduk sampai rata hingga menjadi gel warna kuning. Screen yang sudah bersih dan kering dilapisi obat peka cahaya dilakukan pada ruang gelap sampai rata pada dua sisi bagian luar screen dan bagian dalam. Dengan menggunakan penggaris plastik, mika atau alat yang ada pada dus obat peka cahaya atau apapun yang sifatnya meratakan. Jangan sampai ada bagian yang terlalu tebal atau tipis karena bisa mengganggu hasil afdruk. Kemudian dikeringkan menggunakan hairdryer, kipas angin atau open pengering. Pengeringan berfungsi untuk memperkuat perekatan obat afdruk dengan kain screen, hal ini masih dilakukan pada ruang peka cahaya atau ruang gelap.

\section{Perekaman Film}

\section{Meja Afdruk}

Proses afdruk selain menggunakan sinar matahari dapat juga dilakukan dengan menggunakan meja yang dilengkapi dengan lampu neon atau TL untuk hemat energi (terutama digunakan apabila cuaca mendung atau hujan). Lama waktu penyinaran penyinaran 4 menit atau waktu menyesuaikan dengan obat yang akan diafdruk.

\section{Kaca Bening 2 mm}

Untuk menutup dan menekan kodatrace pada waktu penyinaran dengan sinar matahari atau pada meja afdruk dengan lampu.

\section{Pengeringan}

Pengeringan setelah proses pengolesan obat peka cahaya bisa dengan diangin-anginkan atau menggunakan hairdryer pada ruangan gelap.

\section{Koreksi}

Apabila pada waktu mencuci screen terjadi kerusakan gambar, yaitu lapisan obat yang ada mengekupas, maka bagian tersebut harus segera ditutup dengan obat afdruk dan dikeringkan kembali, pekerjaan ini disebut men-tusir. Agar pada waktu mencetak warna tidak bocor keempat sisi bingkai screen diperkuat dengan dilapisi lakban.

\section{Proses Akhir}

Langkah awal yang perlu diperhatikan dalam proses penyablonan adalah karakteristik bahan yang akan disablon. Semua benda yang akan disablon memiliki sifat yang berbeda antara yang satu dengan yang lainnya. Hal ini perlu diketahui agar pada waktu penyablonan kita dapat dengan benar menggunakan screen dan tinta yang cocok dengan sifat benda tersebut.

\section{Produksi Cetak}

\section{Setting}

Dalam prakteknya, sebelum menyablon adalah memasang screen pada catok. Kemudian beri tanda patokan posisi benda (anleg) berupa pengeleman kertas membentuk siku. Patokan posisi sablon ini dibuat dengan cara menyablonkan pada kaca meja sablon kemudian diberi tanda anleg atau register tab.

\section{Papan Landasan}

Papan landasan terdiri dari Triplek sebagai penyangga screen pada waktu afdruk, sedangkan papan yang dilapisi busa dan blanket dilapisi perekat atau lem kain (Hidronal G). dan sebagai papan landasan pada penyablonan T-Shirt atau kain yang ukurannya sesuai. 


\section{Meja Sablon}

Meja untuk menyablon kaos atau lembaran yang ukurannya kecil, dilengkapi dengan klem penjepit dan dapat diputar, cukup untuk empat screen.

\section{Proses Cetak}

Setelah patokan posisi benda terpasang dengan baik maka berikutnya tuangkan cat di atas screen kemudian, lakukan penggosokan dari arah catok ditarik ke arah badan kita. Cara ini bisa berlainan setiap orang bergantung kebiasaan masing-masing. Demikian seterusnya, hingga produksi cetakan sablon selesai.

\section{Finishing}

\section{Pencucian}

Setelah selesai screen dapat dicuci dengan M3 dengan menggunakan kain perca katun atau kapas (jika sablon solvent base) tetapi jika penyablonan water base (cat tekstil diatas kain) maka pencuciannya cukup menggunakan air.

\section{Penghapusan}

Proses ini sangatlah mudah, siapkan oles dan gosok remover pada seluruh permukaan screen. Karena bahan ini mengakibatkan iritasi pada kulit Biarkan kurang lebih 3 sampai dengan 6 menit, kemudian semprotkan air deras pada permukaan screen hingga screen bersih kembali.

\section{PENUTUP}

Teknik cetak sablon mempunyai karakteristik yang berbeda. T-shirt sebagai media cetak sablon sangat efektif dalam mendukung promosi dan media apresiasi karya desain.

\section{DAFTAR PUSTAKA}

Nusantara, G. (2007). Panduan praktis cetak sablon. Jakarta: Kawan Kita.

Rivers, W. L., Jensen, J. W., \& Peterson, T. (2003). Media Massa dan Masyarakat Modern, Edisi Kedua, Jakarta: Prenada Media. 